\title{
Optimal control and operation of a GSHP system for heating and cooling in an office building
}

\section{Javier Cervera-Vázquez Antonio Cazorla-Marín}

\author{
Carla Montagud
}

\author{
José Miguel Corberán
}

\begin{abstract}
Ground source heat pump (GSHP) systems are widely considered as being among the most efficient heating and cooling renewable technologies currently available. Nevertheless, both an optimal design of components and an optimal operation of the system as a whole become crutial in order to contribute to an attenuation of the global warming potential of this kind of installations.

The overall objective of this research work is to perform the control and energy optimization of an experimental GSHP system installed at the Universitat Politècnica de València, located in València (Spain), making the control system adaptive to the thermal demand of the building and to the climate conditions.

The optimization of any system requires a comprehensive study of its behaviour, by means of a thorough analysis of all the variables and parameters implied on its performance. Therefore, as a first step, both the short-term and long-term performance based on the experimental data collected at the installation will be analyzed. Finally, the different control strategies that have been developed, implemented and experimentally tested in the system will be described. These strategies' focus is not in optimizing the performance of each individual component, but in optimizing the energy performance of the system working as a whole, while keeping the user comfort. Experimental results for a one-year operation period demonstrate important energy savings, up to $35 \%$ in the summer season and $53 \%$ in the winter season.
\end{abstract}

\section{INTRODUCTION}

The use of ground source heat pump (GSHP) systems can lead up to a $40 \%$ energy savings for a one year operation period compared to conventional air-to-water heat pumps (Urchueguía, et al. 2008). However, when considering the system as a whole including the auxiliaries' consumption and not only the heat pump, an integrated optimal operation is required. In this context, the adaptation of the heat pump capacity and the auxiliaries' operation to the thermal energy demand of the building is crutial. Some examples focused on capacity control by means of variable speed compressors were presented by Fahlén and Karlsson, (2003; 2005). In the case of GSHP systems, Edwards and Finn (2015) developed a control strategy and implemented it in a simulation model to predict optimal GSHP water flow rates for single speed and tandem speed heat pumps under part load operation. Del Col, et al. (2014) analyzed the energy performance of an existing GSHP installation with variable speed compressor, variable speed water circulation pumps and variable speed fans in the coils. Marmaras, et al. (2016) developed a control algorithm to optimize the water 
circulation pumps' operation in a de-coupled primary-secondary existing GSHP system. Montagud, et al. (2014) developed an experimental in situ optimization methodology for the water circulation pumps frequency of single stage ON/OFF GSHP systems, which was also adapted to multi-stage (Cervera-Vázquez, et al. 2015a) systems. Results led to the development of an energy optimization algorithm combined with an outdoor temperature reset strategy. Its implementation in the control board of the system allowed keeping both the setpoint of the heat pump and the flow rates of the water circulation pumps at an optimal combination (Cervera-Vázquez, et al. 2014). After running the system during a whole year, experimental results were analyzed and the optimized control was compared to a standard one. Energy savings around 30\% were obtained depending on the analyzed period (Cervera-Vázquez, et al. (2014; 2015a)). However, after several years of operation, some complaints from the users were found. After a careful analysis of the experimental data, it was detected that the user comfort was not met in extreme summer conditions, being the values of indoor temperature and relative humidity $27^{\circ} \mathrm{C}$ and $70 \%$ respectively. To overcome this issue, a new upgraded optimized control was developed to keep the system working at its optimal point and also meeting the user comfort. This new algorithm was implemented in the control board of the system and tested during one whole cooling season (May - October 2015) and one heating season (November 2015 - February 2016). This research work describes the upgrade of the former integrated optimization strategy and presents the results for both heating and cooling mode. A previous analysis was done during the cooling season (Cervera-Vázquez, et al. 2015b).

\section{GEOTHERMAL EXPERIMENTAL PLANT}

The geothermal installation studied in this paper was built in year 2005 in the framework a European project called GEOCOOL (Geothermal Heat Pump for Cooling and Heating along European Areas, contract number NNE52001-00847). Since then, the installation has been completely monitored. In the framework of another European project, GROUND-MED (Advanced ground source heat pump systems for heating and cooling in Mediterranean climate, contract number TREN/FP7EN/218895), different energy optimization studies were carried out during years 20092013. The experimental plant air-conditions a set of spaces in the Department of Applied Thermodynamics at the Universitat Politècnica de València, Spain, covering a total floor area of approximately $250 \mathrm{~m}^{2}$, and includes a corridor, nine offices (located on the east façade of the building), a computer room and a service room with office equipment and other internal loads. Each office, along with the service room, is equipped with one fan coil, except for the computer room which has two fan coils installed. The corridor is not air conditioned. Each fan coil can be individually regulated by means of a thermostat; and comfort temperature and fan speed can be manually selected by the user. The control

for each fan coil is governed by a three-way valve that allows the heating/cooling water to be modulated through the fan coil. The valve is controlled by the thermostat of the room. Each room has a fan coil unit supplied by the GSHP system. The GSHP system mainly consists of a reversible water-to-water GSHP, a ground source heat exchanger (GSHX) and two hydraulic loops (one for the internal loop coupled to the building, and another one for the external loop coupled to the ground). A diagram of the installation can be found in (Cervera-Vázquez, et al. (2015b)) . The GSHP currently installed, is a prototype unit developed and manufactured in the framework of the GROUND-MED project. It consists of a water-to-water reversible GSHP, which uses R410A as refrigerant. The heat pump is reversible both on the refrigerant and on the secondary fluid circuits thanks to the use of water reversing valves, in such a way that it always works in counter current conditions resulting in a higher efficiency. The nominal heating and cooling capacities are $18 \mathrm{~kW}\left(35^{\circ} \mathrm{C}\right.$ building return $/ 17^{\circ} \mathrm{C} \mathrm{GSHX}$ return) and $15.4 \mathrm{~kW}\left(14^{\circ} \mathrm{C}\right.$ building return $/ 25^{\circ} \mathrm{C}$ GSHX return) respectively. In order to better adapt the GSHP capacity to the building thermal load, the GSHP has two scroll compressors of the same capacity working in tandem. The evaporator and condenser are two brazed plate heat exchangers of the same geometry with 42 plates each. The (GSHX) consists of 6 vertical borehole heat exchangers (grid of $2 \times 3$ boreholes, $50 \mathrm{~m}$ deep, $3 \mathrm{~m}$ separated from each other); each borehole contains a single polyethylene U-tube of $25.4 \mathrm{~mm}$ internal diameter, with a $70 \mathrm{~mm}$ separation between the upward and downward tubes.

The system is divided into two hydraulic circuits. The internal one consists of 12 parallel-connected fan coils, an internal hydraulic loop and a water storage tank. The external one consists of the GSHX which is coupled to the heat 
pump by an external hydraulic loop. The system operates from 7 a.m. to 8 p.m. during 5 days per week. Both circuits have circulation pumps, in order to pump the water to the fan coil units (internal circulation pump (ICP); nominal values at $50 \mathrm{~Hz}: 3180 \mathrm{~kg} / \mathrm{h}, 0.63 \mathrm{~kW}$ ) and the GSHX (external circulation pump (ECP); nominal values at $50 \mathrm{Hz:} 2650 \mathrm{~kg} / \mathrm{h}$, $0.36 \mathrm{~kW}$ ). The ICP operates continuously along the day, whereas the ECP only works when at least one of the compressors of the GSHP is running. The water flow rate in both circuits can be varied by two frequency inverters. A network of sensors was set up so that the installation is completely monitored: water temperatures (four-wire PT100 with accuracy $\pm 0.1^{\circ} \mathrm{C}$.), mass flow rates (Danfoss flow meter model massflo MASS 6000 with accuracy $<0.1 \%$ ) and power consumptions (Gossen Metrawatt power meter model A2000 with accuracy $\pm 0.5 \%$ ). A more detailed description of the system can be found in previous publications (Ruiz-Calvo and Montagud 2014; Cervera-Vázquez, et al. 2015a).

\section{OPTIMIZATION METHODOLOGY FOR THE WATER CIRCULATION PUMPS FREQUENCY AND TEMPERATURE COMPENSATION}

The authors previously developed an experimental in situ optimization methodology for the water circulation pumps frequency (Cervera-Vázquez, et al. 2015a). Its main advantage is that it is based on experimental measurements and it can be carried out in situ at any installation. Therefore, it is able to take into account the real characteristics of the installation as well as real operating conditions. A summary of this methodology, which consists of three steps, is presented in this subsection.

The first step consists of several experimental tests of pseudo-random sequence of frequency steps, sweeping both circulation pumps (one corresponding to the building hydraulic loop to supply the hot/cold water to the terminal units, and another one on the GSHX hydraulic loop) frequencies in the range of operating frequencies (from $20 \mathrm{~Hz}$ to $55 \mathrm{~Hz}$ ). Through this step it is intended to characterize the performance of the system during the ON time operation of the compressor. Since the heat pump consists of two compressors working in tandem, the tests must be repeated when there is only one compressor cycling $\mathrm{ON} / \mathrm{OFF}$ or one compressor continuously running and the other one cycling ON/OFF.

The second step consists of analyzing the results obtained from step 1, estimating the system COP under quasisteady state conditions (only the ON cycle) and finally representing the values of the COP in a contour map as a function of both circulation pumps frequencies.

The third step allows taking into account the influence of the internal circulation pump and the parasitic losses during the OFF cycle calculating, from the quasi-steady state performance maps obtained in step 2 of the methodology, the optimal frequencies as a function of the thermal demand of the building. The thermal demand of the building is represented by the partial load ratio of the system $(\alpha)$, which can be defined as the relation between the instantaneous thermal load of the building and the heat pump capacity. This step finally provides the system performance factor as a function of the partial load ratio of the system for different values of both circulation pumps frequencies. A sample of the resulting contour maps is shown in (Cervera-Vázquez, et al. 2015b). From these maps, expressions which provide the optimal values of both circulation pumps' frequencies as a function of the partial load ratio can be obtained and implemented in the control board of the system. It should be noted that, in order to provide a stable control, the values of the partial load ratio considered in the control algorithm are not instantaneous values. They are calculated for each working cycle of the heat pump according to the following equation:

$$
\alpha=\frac{\sum_{n=0}^{n=N} n \cdot t_{O N_{C, n}}}{N \cdot\left(t_{C}\right)}
$$

According to Eq.(1) the partial load ratio can be defined as a weighted average of the number of compressors switched on (n), depending on the amount of time each compressor works during the cycle $\left(t_{O N_{C, n}}\right)$, and taking into account the total number of compressors of the heat pump $(\mathrm{N})$ and the total working time of the cycle (tc). Further details about this calculation can be found in Ruiz-Calvo, et al. (2016). These parameters are measured thanks to the 
heat pump control board which provides a signal that indicates the state of each compressor during the GSHP operation.

In order to complete the optimized control, the setpoint of the heat pump, which uses the building supply temperature to control the starts and stops of the compressors, is also varied according to a simple outdoor temperature reset strategy. The controlled variables are the temperature setpoint of the heat pump $\left(T_{S B}\right)$ and the frequency of both the internal $\left(f_{I C P}\right)$ and the external $\left(f_{E C P}\right)$ circulation pumps. The measured variables are the ambient temperature $\left(T_{a m b}\right)$ and the partial load ratio of the system $(\alpha)$. The temperature setpoint of the heat pump was determined as a function of the ambient temperature solely; so, the higher is the ambient temperature, the lower the temperature setpoint is set at the heat pump controller. On the other hand, the circulation pumps' frequencies were calculated as a function of the partial load ratio solely, as it was determined from the three-step methodology. The higher the load ratio, the higher frequency values were set at the frequency inverters, and hence the water flow rates at both hydraulic circuits.

The objective of the control algorithm is to optimize the energy performance of the system, represented by the system performance factor $\left(P F_{s y s}\right)$ defined as the relation between the useful thermal energy supplied to the building $\left(\dot{Q}_{\text {useful_IC }}\right)$ and the system energy consumption including both the heat pump and the circulation pumps' consumption as expressed in Eq. (2).

$$
P F_{s y s}=\frac{\int_{0}^{t} \dot{Q}_{u s e f u l \_I C} \cdot d t}{\int_{0}^{t}\left(\dot{W}_{H P}+\dot{W}_{E C P}+\dot{W}_{I C P}\right) \cdot d t}
$$

Finally, the value of the ICP frequency which optimizes the performance factor of the system was calculated, by means of the experimental methodology developed, in terms of the partial load ratio of the system $(\alpha)$, and the building supply temperature was determined as a function of the ambient temperature $\left(T_{a m b}\right)$ as a first control attempt.

As presented in (Cervera-Vázquez, et al. 2015a), this optimized control was implemented in the control board of the system and tested on the geothermal experimental plant for a period of several months. Results showed that energy savings of $(31.70 \pm 0.07) \%$ were obtained by applying the optimized control, when comparing to a standard control consisting of a fixed frequency value of $50 \mathrm{~Hz}$ for both circulation pumps and a setpoint of $10^{\circ} \mathrm{C}$ in cooling mode and $40^{\circ} \mathrm{C}$ in heating mode. However, it was found that user comfort was not met in extreme weather conditions during the summer. This is mainly becasue the influence of decreasing the internal water flow rate was not taken into account in the fan coil effectiveness, what resulted in the comfort of the user not being met. This happened because both control strategies were uncoupled, that is to say, they worked independently of what each other did. In order to find the optimal values of the controlled variables, namely the internal circulation pump frequency $\left(f_{I C P}\right)$ and the building supply temperature $\left(T_{S B}\right)$, that optimize the performance factor of the system while being able to meet the user comfort, it is necessary to couple both strategies. In the former control, the supply building temperature was calculated as a function of the ambient temperature solely $\left(T_{S B}=f\left(T_{a m b}\right)\right.$ ), whereas the internal frequency was determined considering only the partial load ratio $\left(f_{I C P}=f(\alpha)\right)$. Now both control parameters need to be determined as a function of both variables, the ambient temperature and the partial load ratio of the system $\left(f_{I C P}=f\left(T_{a m b}, \alpha\right)\right)$ and $T_{S B}=f\left(T_{a m b}, \alpha\right)$. For a start, the performance factor of the system will depend on the controlled variables: internal circulation pump frequency and supply building temperature $\left(P F_{s y s}=f\left(f_{I C P}, T_{S B}\right)\right)$. Its variation can be expressed as the sum of the partial derivatives of the system performance factor with each one of the variables.

$$
\left.\frac{\partial P F_{s y s}}{\partial f_{I C P}}\right|_{T_{S B}}+\left.\frac{\partial P F_{s y s}}{\partial T_{S B}}\right|_{f_{I C P}} \cdot \frac{d T_{S B}}{d f_{I C P}}=0
$$

The supply building temperature $\left(T_{S B}\right)$ is calculated according to Eq. (4), as a function of the room temperature $\left(T_{\text {room }}\right)$, the ambient temperature $\left(T_{a m b}\right)$, the parameter $\beta$ (Eq. (5)), the maximum effectiveness of the fan coil $\left(\varepsilon_{F C, \max }\right)$ 
and the correlation of the fan coil effectiveness in terms of the internal frequency and the building supply temperature $\left(\varepsilon_{F C}\left(f_{I C P}, T_{S B}\right)\right)$. This expression is very similar to the one obtained for cooling mode (Cervera-Vázquez, et al. 2015b). A more detailed explanation can be found in (Cervera-Vázquez 2016).

$$
\begin{gathered}
T_{S B}=T_{\text {room }}+\frac{\beta \cdot \varepsilon_{F C, \text { max }} \cdot\left(T_{\text {room }}-T_{\text {amb }}\right)}{\varepsilon_{F C}\left(f_{I C P}, T_{S B}\right)} \\
\beta=\frac{T_{\text {room }}-T_{S B, \text { min }}}{T_{\text {amb,max }}-T_{\text {room }}}
\end{gathered}
$$

In order to calculate the building supply temperature, the value of the internal frequency resulting from the control surfaces (Cervera-Vázquez 2016) is considered and Eq. (4) is solved for $T_{S B}$ (2nd order equation, the negative root is the right solution, as in cooling mode). However, there are both an upper and a lower limit in the setpoint that should not be overpassed. The upper limit is $45^{\circ} \mathrm{C}$. There is no need to supply the water to the building at a temperature higher than $45^{\circ} \mathrm{C}$, as it would not mean any improvement in the user comfort but it would mean higher energy consumption. The lower limit is $35^{\circ} \mathrm{C}$. It does not make sense to supply the water at a temperature lower than $35^{\circ} \mathrm{C}$, as it would be better to turn off the heat pump instead. As far as the lower limit is concerned, there is no problem in setting a temperature higher than the one calculated. The energy savings will not be so important, but the user comfort will still be met. However, if the algorithm calculates a value of $T_{S B}$ higher than $45^{\circ} \mathrm{C}$ (which is unlikely to happen considered the mild winters in Valencia), but the setpoint is set to $45^{\circ} \mathrm{C}$, the user comfort might not be met. That is the reason why, in case that this happens, the internal frequency should be recalculated by means of Eq. (4). Solving Eq. (4) for $f_{I C P}$ and considering a $T_{S B}=45^{\circ} \mathrm{C}$, will provide the corrected value of the frequency (higher than the previous) that will allow the system to meet the user comfort. Figure 1 shows a flow diagram of the optimized control implemented in the control board of the system for the case of heating mode. The flow diagram of the new optimized control for heating mode presents the same structure than for cooling mode (Cervera-Vázquez, et al. 2015b). In fact, they have the same structure. The main difference lies in the equation used for the calculation of the building supply temperature. The other difference is the temperature limit for $T_{S B}$, which is $45^{\circ} \mathrm{C}$, instead of $7^{\circ} \mathrm{C}$.

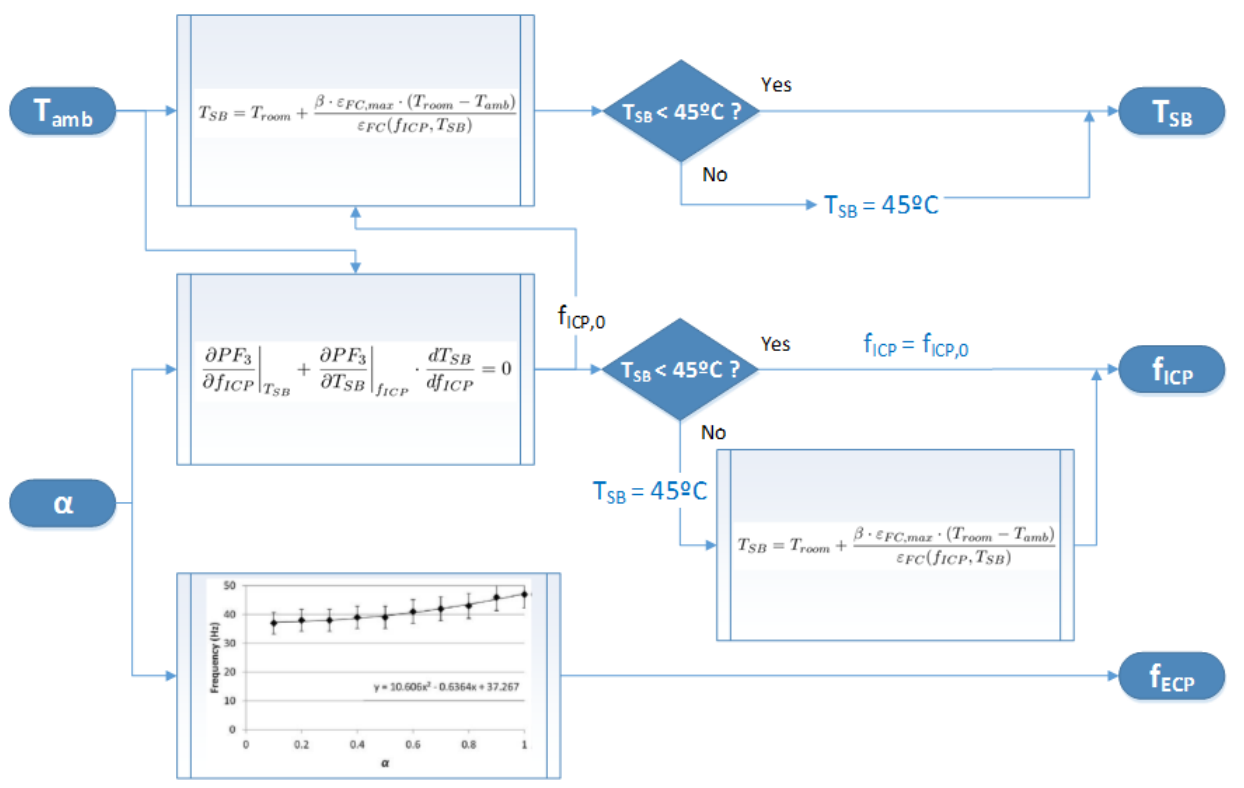

Figure 1 Flow diagram of the new optimized control (heating mode). 


\section{DISCUSSION OF RESULTS}

Results for one typical heating day are presented in Figure 2. The structure of the figure is the same as for cooling mode (Cervera-Vázquez, et al. 2015b). Figure 2a, depicts the power consumption of the compressor and the system temperatures, whereas Figure 2b shows the partial load ratio and the circulation pumps' frequencies.

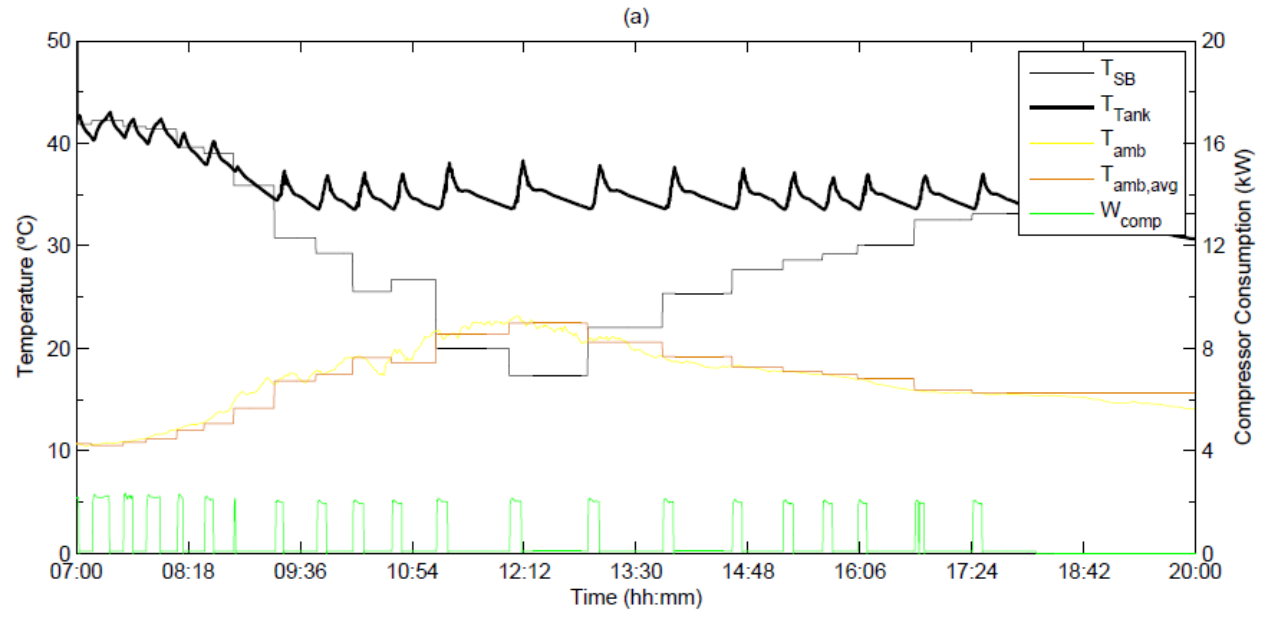

(b)

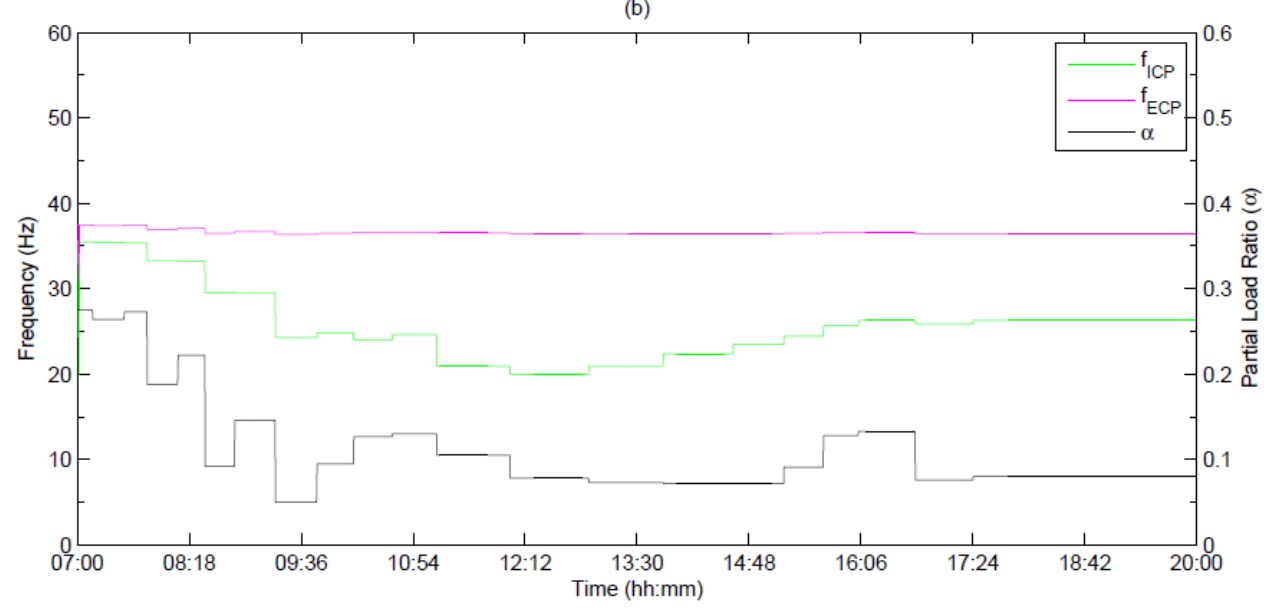

Figure 2 Experimental results of the upgraded integrated control (heating mode).

As it can be observed in Figure 2a, the higher the ambient temperature, the lower the temperature of the water supplied to the building. When the calculated $T_{S B}$ is lower than $35^{\circ} \mathrm{C}$, the limit applies and the actual supply temperature $\left(T_{\text {tank }}\right)$ cycles around $35^{\circ} \mathrm{C}$. It can be observed that the building supply temperature does not get the limit value of $45^{\circ} \mathrm{C}$ at any time. The reason for this is that the last winter has been very mild in Valencia and there are no days in which that limit value has been reached.

Regarding the frequencies, the set values are directly proportional to the value of the partial load ratio. This can be observed in Figure $2 \mathrm{~b}$. On the other hand, a positive users' feedback was received, and the temperature and relative humidity in two selected rooms was observed to be inside the acceptable comfort range according to Spanish 
regulations: $\left[23^{\circ} \mathrm{C}, 25^{\circ} \mathrm{C}\right]$ and $\left[45 \%, 60^{\circ}\right.$ ] , for cooling mode; $\left[21^{\circ} \mathrm{C}, 23^{\circ} \mathrm{C}\right]$ and $[40 \%, 50 \%]$, for heating mode. So, the main target of this new optimized control which was to meet user comfort while saving as much energy as possible, was finally reached.

Regarding the energy savings, in order to carry out a proper energy optimization analysis, the optimized control has been compared to a standard control, as it was done for the first approach to the integrated control, consisting of a temperature setpoint of $7^{\circ} \mathrm{C}\left(45^{\circ} \mathrm{C}\right.$ for heating mode $)$ and $50 \mathrm{~Hz}$ of frequency for both circulation pumps, according to the GSHP manufacturer recommendations. This standard control is slightly different from the one employed for the first approach, due to the specifications of the GROUND-MED project, where the minimum setpoint allowed was $10^{\circ} \mathrm{C}$ for cooling mode and $40^{\circ} \mathrm{C}$ for heating mode, according to the targets of the project.

The same automatic control in the control board of the system has been employed in such a way that the standard control is applied on odd days and the optimized control is used on even days, in order to finally obtain $50 \%$ of the days working with each type of control algorithm.

Figure 3 shows the values of the daily performance factors DPFs (integration period equal to 24hours) from $D P F_{1}$ to $D P F_{3}$, for the period analysed, that is to say, from November 2015 to February 2016. $D P F_{1}$ considers only the heat pump consumption, $D P F_{2}$ includes also the consumption of the external circulation pump and finally $D P F_{3}$ adds the consumption of the internal circulation pump, being this factor the daily system performance factor $\left(D P F_{s y s}\right)$.

The alternation of standard and optimized days can only be seen from January onwards. The explanation to this is that the implementation and tuning up of the upgraded algorithm in the control board of the system came with a delay of one month since the beginning of the season (November). Therefore, in an attempt to equal the number of standard days obtained in November, the optimized control was applied on a daily basis during the month of December. Still, in the case of heating mode a similar or even higher improvement in $D P F_{3}$ can be observed.

Figure 3 shows DPFs calculated for each day in the analysed period. Getting together the standard days on one hand, and the optimized days on the other hand, a kind of Seasonal Performance Factor (SPF) can be obtained as the relation between the useful energy transferred to the building and the energy consumption for each of the different types of control over the period where each one was applied. This way, the improvement achieved by the optimized control when compared to the standard control can be analysed for both seasons. Figure 4 presents this comparison: Figure $4 \mathrm{a}$, for cooling mode and Figure $4 \mathrm{~b}$ for heating mode. When compared to the results of the first approach, it can be observed that the improvement on $S P F_{1}$ (heat pump seasonal performance factor) is more representative with the upgrade. This is because a better control of the heat pump setpoint is achieved with the new optimized control.

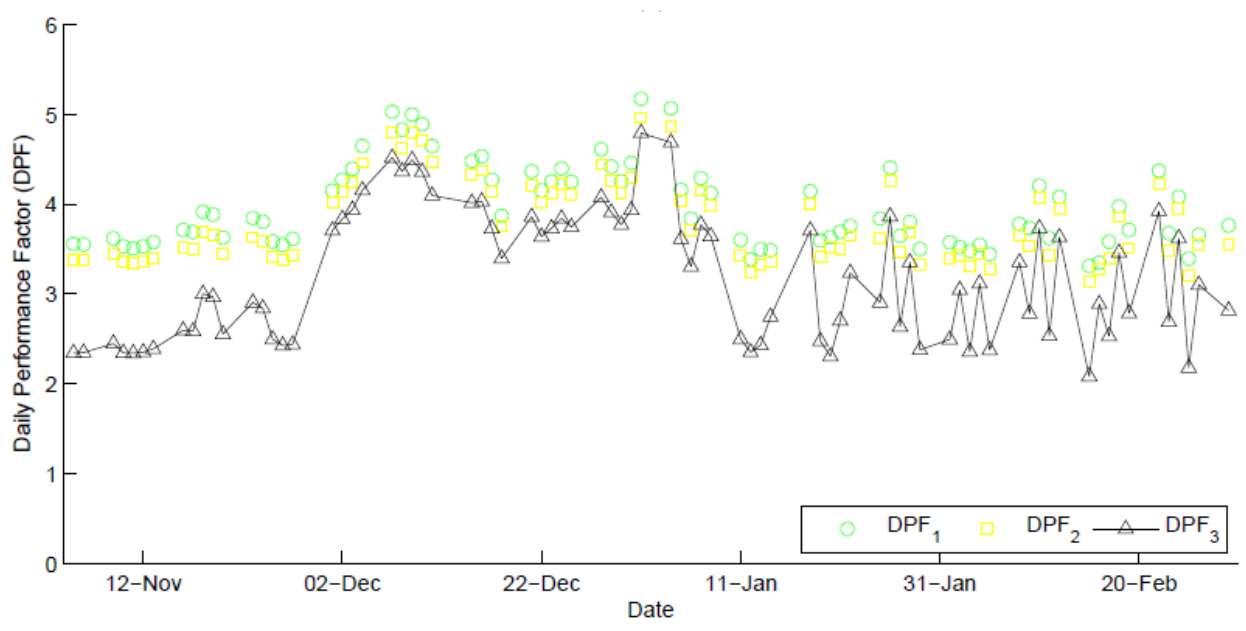

Figure 3 Daily performance factor (upgrade). Heating mode campaign. 
However, the interest should be on $S P F_{3}$ which is the system seasonal performance factor as it considers the energy consumption of all the system components except the terminal units, it is to say, it includes the energy consumption of the heat pump and both circulation pumps. Therefore, it is the performance factor that expresses the energy savings in a more reliable way. In the case of cooling mode, this improvement is $35 \%$, which is slightly worse than with the first approach. In the case of heating mode, a $53 \%$ improvement is obtained in $S P F_{3}$. It should be noted that the difference in the percentage of improvement when compared to the first approach, above all in heating mode (which presented an improvement of $32 \%$ ), is mainly due to two reasons. First, the standard control considered in the first approach was more restrictive, due to the requirements of GROUND-MED project, whereas the one considered when the upgraded algorithm was tested was a more realistic standard control suggested by the heat pump manufacturer. And second, this winter season has been especially mild in Valencia, which means lower thermal energy loads and therefore lower partial load ratios, what has led to a higher improvement of the energy performance. Finally, it should be noted that the impact of the outside temperature and the building occupation in the energy savings cannot be isolated and the energy savings might change from year to year. This is why they need to be measured and checked year by year.
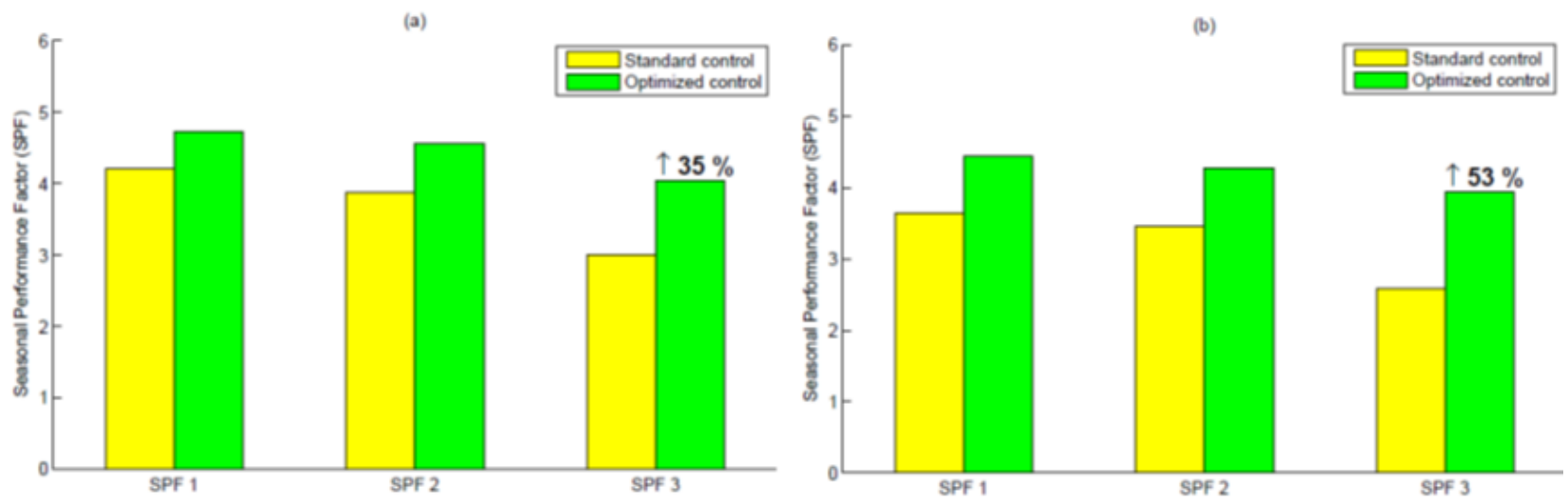

Figure 4 System seasonal performance factor (upgrade): (a) cooling mode test campaign; (b) heating mode test campaign.

\section{CONCLUSIONS}

A new upgraded control algorithm to keep the system working at its optimal point and also meeting the user comfort was developed, implemented and tested in heating and cooling mode in a real GSHP installation located at the Universitat Politècnica de València in Valencia, Spain. The new control approach is based on coupling the estimation of the optimal values of the internal circulation pump frequency and the building supply temperature so that the system is able to work under the minimum energy consumption, provided that the fan coils have a capacity such as to cover the thermal demand and meet the user comfort even in extreme weather conditions. The values of both controlled variables (internal circulation pump frequency and building supply temperature) are calculated as a function of both the ambient temperature (outdoor conditions) and the partial load ratio of the system (thermal load conditions), making the geothermal system smart and adaptive to actual operating conditions. The energy optimization methodology developed in this work is perfectly applicable to any other ground source heat pump installations of the same type. Results show an improvement in the seasonal performance factor of the system up to $35 \%$ in cooling mode and $53 \%$ in heating mode. 


\section{REFERENCES}

Cervera-Vázquez, J., Montagud, C., and Corberán, J. M. 2014. Analysis of the energy performance and control optimization of a GSHP installation, ASHRAE Transactions, 120: 334-345.

Cervera-Vázquez, J., Montagud, C., and Corberán, J. M. 2015a. In situ optimization methodology for the water circulation pumps frequency of ground source heat pump systems: Analysis for multistage heat pump units, Energy and Buildings, 88: 238-247.

Cervera-Vázquez, J., Montagud, C., and Corberán, J. M. 2015b. In situ optimization methodology for ground source heat pump systems: Upgrade to ensure user comfort, Energy and Buildings, 109: 195-208.

Cervera Vázquez, J. 2016. Control and energy optimization of ground source heat pump systems for heating and cooling in buildings, PhD thesis, Universitat Politècnica de València. Available online at: https://riunet.upv.es/handle/10251/66748.

Del Col, D., Azzolin, M., Benassi, G., and Mantovan, M. 2014. Experimental analysis ofoptimal operation mode of a ground source heat pump system, Energy Proc. 45: 1354-1363.

Edwards, K.C. and Finn, D.P. 2015. Generalised water flow rate control strategy for optimal part load operation of ground source heat pump systems, Appl.Energy 150: 50-60.

Fahlén, P., and Karlsson, F. 2003. Improving efficiency of bydronic heat pump heating systems, 21st International Congress of Refrigeration, Washington, USA.

Fahlén, P., and Karlsson, F. 2005. Optimižing and controlling media flows in heatpumpsystems, 8th IEA Heat Pump Conference, Las Vegas, USA.

Marmaras, J., Burbank,J., and Kosanovic, D.B. 2016. Primary-secondary de-coupled ground source heat pump systems coefficient of performance optimization through entering water temperature control, Applied Thermal Engineering 96: 107-116.

Montagud, C., Corberán, J. M., and Montero, Á. 2014. In situ optimization methodology for the water circulation pumps frequency of ground source beat pump systems, Energy and Buildings 68: 42-53.

Ruiz-Calvo, F., and Montagud, C. 2014. Reference data sets for validating GSHP system models and analyzing performance parameters based on a five-year operation period, Geothermics 51: 417-428.

Ruiz-Calvo, F., Cervera-Vázquez, J., Montagud, C., and Corberán, J. M. 2016. Reference data sets for validating and analyzing GSHP systems based on an eleven-year operation period, Geothermics 64: 538-550.

Urchueguía, J. F., Zacarés, M., Corberán, J. M., Montero, Á., Martos, J., and Witte, H. 2008. Comparison between the energy performance of a ground coupled water to water heat pump system and an air to water heat pump system for heating and cooling in typical conditions of the European Mediterranean coast, Energy Conversion and Management 49: 2917-2923. 